\title{
Türkiye'de Kirlilik Yaratan Sektörlerin Dış Ticaretinin Analizi
}

\author{
The International Trade Analysis of Turkey's Polluting Industries
}

\section{Cihat KÖKSAL' $\odot$, Güldenur ÇETIN² $\odot$}

öz

Bu çalışmanın amacı kirlilik yaratan sektörlerin dış ticaretini kirlilik sığınağı hipotezi kapsamında doğrudan yabancı yatırımlar ve ekonomik büyüme gibi değişkenler kullanarak test etmek ve Türkiye örneğinden yola çıkarak diğer gelişmekte olan ülkeler için politika önerileri sunmaktır. Bu çalışma, çok değişkenli regresyon modeli ile 1985-2017 dönemlerine ait yıllık verileri analiz edilerek gerçekleştirilmiştir. Yapılan ampirik testler sonucunda Türkiye'nin incelenen dönemler içinde kirlilik üreten sektörlerde, çevresel düzenlemelerin çok sıkı olmamasından dolayı daha cazip bulunduğu ve doğrudan yabancı yatırımlar aracılığıyla bu sektörlerde daha fazla ihracat yapar hale geldiği görülmektedir. Analiz sonuçlarına göre Türkiye'nin, ilgili dönem için kirlilik sığınağı şeklinde nitelendirilebileceği ortaya konmuş olup, bu kapsamda çeşitli politika önerileri geliştirilmiştir.

Anahtar Kelimeler: Kirlilik sığınakları hipotezi, Kirlilik hale hipotezi, Uluslararası ticaret, Doğrudan yabancı yatırımlar, Ekolojik ayakizi

Jel Sınıflaması: E00, F10, F40

\section{ABSTRACT}

The aim of this study is to test the international trade of Turkey's polluting sectors using variables such as foreign direct investments and economic growth within the scope of the pollution haven hypothesis and to present policy recommendations for other developing countries. This study analyzes the annual data for the 1985-2017 period by using the multivariate regression model. As a result of the empirical tests, it is seen that Turkey is more attractive in the polluting sectors because environmental regulations are not very strict during the examined periods, and it has become more likely to export in these sectors through foreign direct investments. According to the analysis results, it has been 1'istanbul Ticaret Üniversitesi, İșletme Fakültesì Uluslararası Ticaret Bölümü, İstanbul, Türkiye

${ }^{2}$ Istanbul Ticaret Üniversitesi, İşletme Fakültesi İktisat Bölümü, İstanbul, Türkiye

ORCID: C.K. 0000-0003-4621-7697; G.Ç. 0000-0003-3341-7016

Sorumlu yazar/Corresponding author: Cihat KÖKSAL,

İstanbul Ticaret Üniversitesi, İşletme Fakültesi Uluslararası Ticaret Bölümü, İstanbul, Türkiye E-posta/E-mail: ckoksal@ticaret.edu.tr

Başvuru/Submitted: 30.04 .2021

Revizyon Talebi/Revision Requested: 11.06.2021

Son Revizyon/Last Revision Received: 23.07.2021

Kabul/Accepted: 24.07 .2021

Atıf/Citation: Koksal, C., Cetin, G. (2021). Türkiye'de kirlilik yaratan sektörlerin dış ticaretinin analizi. Íktisat Politikası Araştırmaları Dergisi - Journal of Economic Policy Researches, 8(2), 257-275.

https://doi.org/10.26650/JEPR.930212 
revealed that Turkey can be qualified as a pollution shelter for the relevant period, and various policy recommendations have been developed in this context.

Keywords: Pollution haven hypothesis, Pollution halo hypothesis, International trade, Foreign direct investments, Ecological footprint

Jel Classification: E00, F10, F40

\section{EXTENDED ABSTRACT}

With the changes and developments in production systems after the industrial revolution, the production of materials in sufficient quantity and quality to meet cross-border demands has also led to increased resource and production facility needs. The increase in the amount of waste, especially with the periods when foreign trade activities accelerated, brought up whether production brings pollution with it for countries. The fact that production, which is the most basic element in achieving the economic growth targets of the countries, is also seen as a factor that harms the environmental conditions of the countries. On the one hand, it pushes the developed countries to shift their dirty industries to the developing countries; on the other hand, it has encouraged the development of environmentally friendly production processes by establishing clean production systems.

The pollution haven hypothesis states that due to the shifting of the production by developed countries to developing countries with the liberalization process in foreign trade, there will be an increase in environmental quality in developed countries. However, in developing countries, pollution will increase, and developed countries will turn into pollution havens.

The basis of the pollution halo hypothesis is that foreign direct investments reduce environmental damage in developing countries. Therefore, the central assumption of the hypothesis, foreign direct investments, will reduce pollution in developing countries.

When the examined literature is evaluated, it is seen that the studies revealing the amount of toxic waste and the trade relationship are predominant, especially in terms of developing countries. In addition to these, some studies examine the subject by classifying the countries according to their incomes and contribute to the literature by addressing the issue of pollution depending on their income levels. When the literature is evaluated in general, it is seen that studies are investigating China, the USA, and African countries. At this point, List and Co (2000) examined the USA and found that the difference in environmental policies between states is significant. Hoffmann, Lee, Ramasamy, and Yeung (2005) found that the difference in environmental policies between states is significant for 112 countries. Atici and Kurt 
(2007) studied Turkey and found that the Pollution Haven Hypothesis is valid. Asghari (2013) studied MENA and found that the Pollution Halo Hypothesis is valid. Kivyiro and Arminen (2014) studied about six countries, and they found that the Pollution Halo Hypothesis is valid for the Democratic Republic of Congo, South Africa, and Zambia. For Zimbabwe and Kenya, the Pollution Haven hypothesis has also been found valid. Fang, Liu, and Gao (2019), Xu, Zhao, Xie, and Zhu (2020), and Cheng, Li, and Liu (2020) studied China and found that the Pollution Haven Hypothesis is valid.

In this study, the Pollution Haven Hypothesis and the Pollution Halo Hypothesis are explained, and the Pollution Haven Hypothesis is tested for Turkey for the 1985-2017 period. In this study, multivariate regression analysis was applied as a method. For this purpose, the Pollution Limit (KH), GDP (GDP), GDP squared (GDP²), Foreign Direct Investment (FDI), Urbanization (URB), Financial Development (FD), and Ecological Footprint (EF) variables were used. Two models were estimated in the study. The first of these is Model 1, where KH is the independent variable and GDP, GDP², FDI, and URB are dependent variables. Accordingly, there is a statistically significant positive relationship between KH and GDP variables. In other words, as economic growth increases, the pollution limit is positively affected. $\mathrm{GDP}^{2}$ and $\mathrm{KH}$ are in a statistically significant and negative relationship. There is a statistically significant and positive relationship between FDI and $\mathrm{KH}$. Accordingly, as foreign direct investments increase, the pollution limits increase significantly. This finding shows us the conclusion that the pollution haven hypothesis is confirmed.

Finally, URB and KH data are statistically significant and positively correlated. As the rate of urbanization increases, the levels of pollution also increase. Since this situation also shows the transition of employment from the agricultural sector to the industrial sectors, these people are primarily employed in the polluting sectors. According to Model 2 regression results, EF is positively affected by GDP. In other words, economic growth creates environmental pollution. This result again confirms the pollution haven hypothesis in the case of Turkey, supporting the findings of Model 1. Financial development data are positively related to environmental pollution. This situation shows that the financial sectors in Turkey do not allocate resources to green sectors that will prevent environmental pollution.

In this respect, some recommendations have been developed for policymakers in Turkey. As seen, ecological footprints and greenhouse gas emissions are on the rise in Turkey. Environmental policies such as a gradual transition to renewable energy in energy production, stricter environmental regulations, and encouraging companies that produce and export based on clean technology will play an essential role in reducing pollution levels. 


\section{Giriş}

Nüfus artışı üretim artışını beraberinde getirirken, artan nüfusa ve farklı ihtiyaçlara cevap verebilen üretim sistemlerine duyulan ihtiyaç da günden güne artmıştır. Bu artış ilk etapta sadece insan ihtiyaçlarının tatmini odaklı gerçekleşirken, çevre ve kaynak sürdürülebilirliği ön planda tutulmamıştır. Kaynak kullanımının artışı beraberinde üretim artışı ve çevreye bırakılan atıkların artışı olarak da etkisini göstermiştir. Üretim sistemleri alanında gerçekleşen yenilikler her geçen gün ihtiyaçların karşılanma hızı ve kapasitesini de artırırken, belirli gelişme düzeyine ulaşan ülkeler açısından sürdürülebilirlik de önem kazanmaya başlamıştır. Bir yandan gelişmekte olan ülkelerin tam sanayileşme çabaları, diğer yandan gelişmiş ülkelerin kendi sürdürülebilirliklerini hem üretim hem çevre hem de kaynak noktasında ön planda tutmaları tüm üretim süreçlerinin kaynak tedarikinden, üretim sonrası süreçlere kadar yeniden gözden geçirilmesine sebep olmaktadır. Gelişmiş ülkeler üretim mekanizmalarını kendi fiziksel sınırları dışına taşıyarak gelişmekte olan ülkelere üretim sistemleri kurmaktadır. Tüm bu gelişmelerin temel sebeplerinden bir tanesi de küreselleşen ticari faaliyetlerdir. Ticari anlamda sınırların neredeyse tamamen ortadan kalkması noktasına ulaşan mevcut yapı, hem kaynak kullanımındaki artış, hem üretim hızı ve kapasitesi artışları hem de üretimin nihai kullanıma ulaştırılması sürecindeki taşıma sistemleri vasıtasıyla kaynak tüketimine ve kirlenmeye sebep oluyor düşüncesi tüm aşamalarda yer alan aktörler için önemli bir husustur. Bu durum da diş ticaret faaliyetlerinin kirlenmeyi tetikleyen önemli bir unsur olup olmadığı sorularına yanıt aranmasına sebep olmaktadir.

Dış ticaretteki artışın kirlenmenin temel kaynaklarından bir tanesi olup olmadığı sorunsalı tartışılırken bir yandan da bu durum nezdinde ülkelerin dış ticaret faaliyetlerinden en büyük payı alma çabaları da büyük önem arz etmektedir. Söz konusu sorulara yanıt arama hususunun ardında ülkelerin kirlenme bahanesini kullanarak dış ticaret faaliyetlerine yön verme çabalarının olup olmadığı sorusunu da ön plana çıkarmaktadır.

Dış ticaret ve kirlilik konularını ele alan literatür kapsamlı olarak değerlendirildiğinde, kirlilik sığınakları ve kirlilik hale hipotezlerine ilişkin tartışmaların varlığı görülmektedir. Söz konusu iki argümanın değerlendirilmesi hem teorik hem de ampirik çalışmalarla yapılırken, ülkeler bazında ya da dönemler bazında farklı sonuçlara ulaşan çalışmalar mevcuttur. Literatürde Kirlilik Sığınağı Hipotezi ilk defa Pethig'in 1976 tarihli çalışmasında kullanılmıştır ve 1990'lı yıllardan itibaren ihracat-ithalat verilerine dayanan analizlerle sınanmıştır. Doğrudan yabancı sermaye yatırımlarının çevresel etkilerinin olumlu olduğu görüşünün yansıması ise Kirlilik Hale Hipotezi'dir. Literatürde yer alan çalışmalar söz konusu iki hipotezi destekleme bakımından iki temel gruba ayrılmaktadır. Kirlilik sığınakları hipotezini inceleyen çalışmalar ağırlıklı olarak doğrudan yabancı sermaye yatırımları 
aracılığıly hipotezi değerlendirmektedir. Sapkota ve Bastola (2017), Xu ve ark. (2020), Cheng ve ark. (2020), Fang ve ark. (2019) Kirlilik Sığınakları Hipotezi’ni destekleyen sonuçlara ulaşırken, Kivyiro ve Arminen (2014) ile Asghari (2013) Kirlilik Hale Hipotezini destekleyen çalışmalar arasında yer almaktadır.

Her iki hipotez hususunda da ağırlıklı olarak Çin'e ilişkin çalışmalar dikkat çekmektedir. $\mathrm{Bu}$ da hem Çin'in bir nevi dünya üretim merkezi unvanını elinde tutma çabaları hem de yoğun dış ticaret hacmi sebebiyle olmaktadır. Türkiye bazında konu değerlendirildiğinde ise Çin kadar yoğun bir yere sahip değildir literatürde. Hem kirlilik sığınakları hem de kirlilik hale hipotezlerinin değerlendirilmesi açısından incelenen dönem bazında bu çalışma literatürdeki söz konusu açığı kapatmayı ve Türkiye için her iki hipotezi de değerlendirmeyi amaçlamaktadır.

Günümüzde Türkiye de dahil olmak üzere ülkeler bir yandan yeşil ekonomi olarak adlandırılan sisteme dahil olmaya çalışırken bir yandan da dünya üretim ve dış ticaret pastalarından en büyük payı almayı, hatta pastaya sahip olmayı amaçlamaktadır. Bu durum ise tüm ülkeler için olduğu gibi Türkiye için de kirliliğin dış ticarete etkileri ve aynı zamanda dış ticaretin de kirliliğe etkileri konularının değerlendirilmesini gerektirmektedir. Bu görüşlerden hareketle çalışmada dış ticaret ve kirlilik ilişkisi incelenmektedir. Söz konusu inceleme yapılırken temel alınan hipotez "Kirlilik Sığınakları Hipotezi”dir. Ancak söz konusu hipotez ele alınırken aynı zamanda "Kirlilik Hale Hipotezi”ne de değinilecektir. Çalışmanın ilk bölümünde çevre ve ticaret ilişkisi açıklanmaya çalışılırken, "Kirlilik Sı̆̆ınakları Hipotezi” ve "Kirlilik Hale Hipotezi” de açıklanacaktır. Çalışmanın ikinci bölümünde ise konuya ilişkin çalışmalar incelenerek hazırlanan literatüre yer verilecektir. Çalışmanın üçüncü bölümünde ise Türkiye açısından "Kirlilik Hale Hipotezi” ampirik olarak test edilecektir.

\section{2. Çevre-Dış Ticaret İlişkisi: "Kirlilik Sığınakları Hipotezi”" ve "Kirlilik Hale Hipotezi"}

Sanayi Devrimi beraberinde üretim artışını da getirmiştir ve üretim artışı çıktı ve atık miktarının da artması anlamına gelmektedir. Özellikle Sanayi Devrimi ve izleyen süreçte kullanılan temel enerji girdisinin fosil yakıtlar olması kirlenmenin de hızla artmasına sebep olmuştur. Ülkeler arası ticari sınırların da hızla ortadan kalkmasıyla talep artışı ve üretimde artış yoğunlaşırken, kaynak tüketimi ve atık miktarı artışı da hız kazanmıştır. Özellikle kirlenmenin ülkelerin gündeminde yer bulabildiği 1960'lı yıllara kadar temel konu ekonomik büyümenin sağlanması olduğu için kirlenme faktörleri göz ardı edilerek üretime ve dış ticarete öncelik verilmiştir. Ancak küresel ısınma ve iklim değişikliği konularının sürdürülebilir büyüme ve kalkınma hedefleri açısından da birer engel teşkil ettikleri, hatta 
insan yaşamı ve ekosistemin devamlılığı için tehlike arz etmeleri sebebiyle göz ardı edilemeyecek unsurlar olduğu anlaşılmıştır.

Dış ticaret faaliyetlerinin artışı, üretim artışını da gerekli kılarken, üretim için temel girdi olan fosil yakıtlardan kaynaklanan $\mathrm{CO}_{2}$ emisyonları da hızla artmıştır. Bu da ülkeleri çevre kirliliğini önlemek ve kaynak sürdürülebilirliğini sağlamak için çeşitli düzenlemeler yapmaya itmiştir. Özellikle gelişmiş ülkeler yaptıkları anlaşmalar ve düzenlemelerin yanı sıra üretim sistemlerini de gelişmekte olan ya da az gelişmiş ülkelere kaydırmışlardır. $\mathrm{Bu}$ durum gelişmiş ülkeler ile gelişmekte olan ülkeler arasındaki kirlilik oranları farkının da hızla açılmasına sebep olmuştur.

Bu noktada Kirlilik Sığınakları Hipotezi dış ticaretteki liberalleşme süreciyle birlikte gelişmiş ülkelerin üretimlerini gelişmekte olan ülkelere kaydırmasının bir sonucu olarak, gelişmiş ülkelerde çevre kalitesi artışı olacağını fakat gelişmekte olan ülkelerde ise kirliliğin artarak bir anlamda gelişmiş ülkelerin kirlilik sığınakları haline dönüşeceklerini ifade etmektedir (Gökalp \& Yıldırım, 2004).

Kirliliğin artışının temel sebebi kirletici üretim olarak tanımlayabileceğimiz üretim süreçleridir. Bir ülkenin kirlilik sığınağı haline gelebilmesi için temel sebep kirletici endüstrilerin mevcudiyetidir. Bu da üretim maliyetleri yüksek olan işletmelerin çevre düzenlemeleri ve çevre koruma yaptırımları daha gevşek olması sebebiyle gelişmekte olan ülkelere yatırımlarını taşımaları ile gerçekleşmektedir (Çetinkaya, 2018). Kirli üretim süreçleri kirli endüstrilere aittir ve kirli endüstriler ise bir birim üretim için yüksek miktarda enerji kullanarak, zehirli atıkları ya da temizleme maliyeti yüksek oranda olan ancak faydası temizleme maliyetinden düşük olan endüstrilerdir (Gökalp \& Yıldırım, 2004).

Buna göre hipotezde ülkelerin karşılaştırmalı üstünlüklerinin özünde çevre politikalarındaki tutumunun yer aldığını ifade etmektedir. Bu noktadan hareketle karşılaştırmalı üstünlük durumu çevre politikalarındaki katılık ya da gevşeklik tarafından belirlenmektedir. Temiz çevre talebinin büyüme talebinden daha düşük olduğu ülkeler, gelişmiş ve çevre bilincinin daha üst düzeyde olduğu ülkelerin üretim merkezleri haline gelmektedir (Şahinöz \& Fotourechi, 2014). Bu hipotezin temel varsayımlarından bir diğeri ise doğrudan yabancı sermaye yatırımları ve karbon emisyonu ilişkisine yöneliktir. Doğrudan yabancı sermaye yatırımları ve karbon emisyonu arasında pozitif bir ilişkinin varlığına vurgu yapılmaktadır. Sebebi ise düşük maliyet ve yüksek üretim birleşimine ulaşabilmek için çevreden ve vergilerden feragat edilmesidir. Bu da ancak yabancı yatırımlar çekilerek gerçekleşebilecektir (Zeren, 2015). Yabancı yatırımların gelişmiş ülkelerden gelişmekte olan ülkelere doğru gerçekleştirilmesi için gelişmekte olan ülkelerin feragat edecekleri çevre standartları ve bu standartları korumaya dair uygulanmayacak yaptırımlar gelişmekte olan 
ülkelerde kirliliğin de hızla artmasıyla sonuçlanacaktır. Nitekim gelişmiş ülke kendi çevre standartlarını korurken bir anlamda da başka ülkelerin kirleticisi konumunda yer almaktadır.

Kirlenme ve ticaret ilişkisi açısından bakıldığında bu konudaki çalışmalarda birbirinden farklı çok sayıda görüşün yer aldığı dikkat çekmektedir. Söz konusu görüşler gruplandırıldığında temelde iki farklı düşüncenin hakim olduğu görülecektir. Bunlardan ilki kirli endüstrilerin gelişmekte olan ülkelerde toplanmasının sebebinin ticaretin serbestleşmesi olduğu görüşüdür, diğeri ise ticarette serbestleşmenin gelişmekte olan ülkelerde kirlenmeye sebep olmadığı görüşüdür (Gökalp \& Yıldırım, 2004).

D1ş ticaret ve çevre kirliliği arasındaki ilişkiyi gösteren en önemli indikatörlerden birisi kirlilik hadleridir. Kirlilik yaratan sektörlerin ihracatının ithalata oranıyla elde edilen kirlilik hadlerini hesaplamak amaciyla SITC Rev.2 kriterlerine göre kirlilik hadleri hesabına dahil edilen sektörler kağıt hamuru (25), petrol rafineleri (33), metalik olmayan mineral (66), demir-çelik (67) ve demir dışı metal (68) şeklinde olmuştur (Çınar, Yılmazer, \& Fazlılar, 2012). Grafik 1'de Türkiye için kirlilik üreten sektörlerin ithalat ve ihracat oranları (kirlilik hadleri) yer almaktadır. Grafik incelendiğinde 1994, 2001, 2008 ve 2018 kriz yıllarında kirlilik hadlerinde düşüşler yaşanmıştır ve takip eden yıllarda hızla eski seviyesinin üzerine çıkarak artmıştır. Bu durum kirlilik üreten sektörlerin ihracatının krizlerde ithalata göre daha sert tepki verdiği ancak kriz sonrasında hızla toparlanarak artışa geçtiğini göstermektedir. Ayrıca Türkiye'de kirlilik yaratan sektörlerin ihracatının 200ç8 yılından sonra hızlı bir şekilde yükselerek 2019 yılı itibarıyla 0.775 seviyesine kadar yükseldiği görülmektedir.

\section{Grafik 1. Türkiye İçin Kirlilik Hadleri}

\section{Kirlilik Haddi}

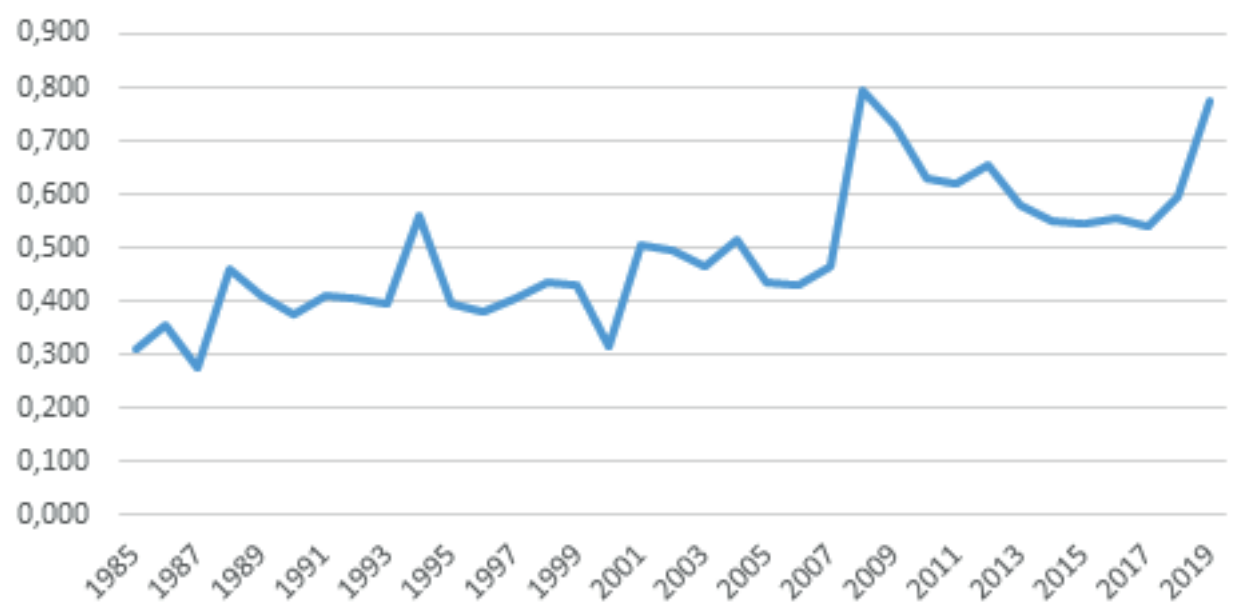

Kaynak: UN Comtrade-Commodity Trade Statistics Database 
Kirlilik hale hipotezinin temelinde ise doğrudan yabancı yatırımların gelişmekte olan ülkelerde çevresel tahribatı azalttı̆̆ı görüşü yer almaktadır (Yıldırım, Destek, \& Özsoy, 2017). Bu hipotezin ise temelinde rekabet gücünü artırma isteğinde olan gelişmiş ülke firmalarının yeni üretim yöntemlerine başvurması ve bunun için de yenilikçi ve çevreye duyarlı üretim sistemleri geliştirmeleri düşüncesi yer almaktadır. Söz konusu yenilikçi ve çevreye duyarlı üretim sistemlerini de yatırım yapacakları ülkelerde kullanmaları sonucunda hipotezin temel varsayımı olan doğrudan yabancı yatırımların gelişmekte olan ülkelerde kirliliği azaltması durumu gerçekleşecektir.

Görüldüğü üzere her iki hipotez de doğrudan yabancı sermaye yatırımlarının gelişmiş ülkelerden gelişmekte olan ülkelere doğru gerçekleştirilmesi düşüncesinden hareket etmektedir. İki hipotezin temel farklılığı ise Kirlilik Sığınakları Hipotezinde gelişmiş ülke kirletici olarak vurgulanırken, Kirlilik Hale Hipotezinde ise gelişmiş ülke kirliliği azaltıcı hatta önleyici etken olarak vurgulanmaktadır.

\section{Literatür}

Çevre kirliliği birden fazla bilim alanını etkilemekle birlikte, günümüzde özellikle ekonomi ve dış ticaret ile olan ilişkisinin düzeyi ve yönü sıklıkla araştırılan bir konudur. $\mathrm{Bu}$ hususta literatürde çok sayıda eser yer almakla birlikte, kullanılan yöntemler farklılıklar göstermektedir. Çalışmanın bu bölümünde dış ticaret-kirlilik ilişkisine dair ve Kirlilik Sığınakları Hipotezine dair literatür incelemelerine yer verilmektedir.

Tobey (1990) çalışmasında zehirli atık miktarının ticaretle bağlantılı olduğuna değinerek, çevre standartları ile endüstrilerdeki kirlilik yoğunluğunun belirlendiğini açıklamıştır. Öte yandan Low ve Yeats (1992) çalışmalarında, kirliliğe sebep olan ürünlerin üretim hacminin gelişmekte olan ülkelerde arttığını ifade etmişlerdir. List ve Co (2000) çalışmalarında gelişmiş ülkelerin yatırımlarla gelişmekte olan ülkelerde üretim yaparak gelişmekte olan ülkeleri kirlilik sığınakları haline getirdikleri görüşünden hareket eden Kirlilik Sığınakları Hipotezini doğrulayan sonuçlara ulaşmışlardır. Hoffmann ve ark. (2005) ülkeleri düşük, orta ve yüksek gelirli olarak sınıflandırdıkları çalışmalarında, doğrudan yabancı sermaye yatırımlarının karbon emisyonunun temel sebebi olduğunu ve orta gelirli ülkeler için ise bu durumun geçerli olmadığını ancak yüksek gelirli ülkeler için ise doğrudan yatırımlarla karbon emisyonu arasında herhangi bir nedensellik bulunmadığını tespit etmişlerdir.

Asghari (2013) çalışmasında, Kirlilik Sığınakları Hipotezinin tam tersini savunan Kirlilik Hale Hipotezinin geçerli olduğunu tespit etmiştir. Keller ve Levinson (1999) çalışmalarında, değişen çevre standartlarının uluslararası yatırım modellerine etkilerini ele almıştır ve kirlilik yoğun endüstrilerde çevresel düzenlemelerin küçük caydırıcı etkilerinin bulunduğunu tespit etmişlerdir. Kivyiro ve Arminen (2014) çalışmalarında altı Sahra Altı Afrika ülkesi 
için $\mathrm{CO}_{2}$ (karbondioksit) emisyonları, enerji tüketimi, ekonomik kalkınma ve doğrudan yabancı yatırımlar arasındaki nedensellik ilişkisini araştırmışlardır ve çevresel kuznets eğrisi hipotezinin desteklendiğini, aksi takdirde, nedensellik ilişkilerinin her ülke için farklılık göstereceğini tespit etmişlerdir. Atıcı ve Kurt (2007) çalışmalarında, Türkiye için dış ticaretçevre ilişkisini incelemişlerdir ve Türkiye için üretim-ihracat artışı ile kirlilik arasında Kirlilik Sığınağı Hipotezini doğrulayan yönde bir ilişki olduğunu tespit etmişlerdir. Sapkota ve Bastola (2017) çalışmalarında, doğrudan yabancı yatırımın (DYY) ve gelirin kirlilik emisyonları üzerindeki etkilerini, 14 Latin Amerika ülkesi için incelemişlerdir ve Kirlilik Sığınakları Hipotezinin geçerliliğini tespit etmişlerdir.

$\mathrm{Xu}$ ve ark. (2020) çalışmalarında, bölgeler arası ticaret faaliyetlerinin Çin'in $\mathrm{CO}_{2}$ emisyonlarını arttırdığını ve Kirlilik Sığınakları Hipotezinin ulusal düzeyde varlığını tespit etmişlerdir. Cheng ve ark. (2020) çalışmalarında Çin'in 285 şehri için 2003-2016 verilerine dayanan doğrudan yabancı yatırımın, PM2.5 kirliliği üzerindeki etkisini analiz etmişlerdir. Kentsel PM2.5 kirliliğinin hem önemli küresel mekansal otokorelasyon hem de yerel mekansal yığılma etkileri gösterdiğini ve Çin>in kentsel PM2.5 kirliliğini önemli ölçüde artırarak Kirlilik Sığınakları Hipotezini doğruladığını tespit etmişlerdir. Fang ve ark. (2019) çalışmalarında, Çin〉in çevresel bilgiyi ifşa politikasının, düzenlenmiş bölgelerdeki endüstriyel firmaların ihracat ölçeği üzerinde azaltıcı olduğunu ve Çin açısından Kirlilik Sığınakları Hipotezinin geçerliliğini göstermişlerdir. Dou ve Han (2019) çalışmalarında, güçlü mobil kirlilik endüstrilerinin gevşek düzenlemelerin olduğu alanlara taşınma eğiliminde olduğunu, fakat "Yenilik Tazminatı" etkisinin bu noktada önemli olmadığını ve kirlilik endüstrilerinin dişarı çıkmasına neden olduğunu tespit etmiştir.

Kirlilik Sığınakları Hipotezi bu açıdan geçerliyken, zayıf hareket eden kirlilik endüstrileri açısından geçerli olmadığı tespit edilmiştir. Xu, Dietzenbacher ve Lo (2020) çalışmalarında ABD için ihracat, emisyonlar ve ithalat yoluyla kaçınılan emisyonları karşılaştırmaktadır. Çalışmada bazı sektörler için ihracattan elde edilen katma değerin yarısından fazlasının çevresel zararlara gittiği ve ABD’nin ihracatını yüksek kirletme oranına sahip ürünlere kıyasla düşük kirletme oranına sahip ürünlerde daha fazla artırarak ticaretten daha fazla yararlanabileceği tespit edilmiştir. Mert ve Caglar (2020) çalışmalarında 1974-2018 dönemi için Türkiye'deki doğrudan yabancı yatırımlar ve emisyonlar arasındaki ilişkiyi analiz etmişlerdir. Çalışmada asimetrik kirlilik cenneti ve asimetrik kirlilik hale hipotezleri açıklanarak test edilmiştir ve sonuç olarak kısa vadede doğrudan yabancı yatırımların pozitif şokları ile emisyonlardaki pozitif hareketler arasında asimetrik bir nedensellik ilişkisi ile uzun vadede doğrudan yabancı yatırımların negatif ve pozitif şokları ile pozitif emisyonlar arasında asimetrik bir nedensellik ilişkisi tespit edilmiştir. Repkine ve Min (2020) çalışmalarında kirlilik hale hipotezini destekleyen güçlü sonuçlar elde etmiştir ve üçüncül sektörlerin bölgesel bir ekonomideki payı ile çevresel verimlilik arasında negatif bir ilişki 
bulmuşlardır. Polloni-Silva, Ferraz, Camioto, Rebelatto, ve Moralles (2021) çalışmalarında, Brezilya'nın Sao Paulo eyaleti için $\mathrm{CO}_{2}$ emisyonları üzerindeki ekonomik büyüme ve doğrudan yabancı yatırımların etkilerini 592 belediye için incelemişlerdir ve kişi başına Gayri Safi Yurtiçi Hasıla (GSYİH) ile $\mathrm{CO}_{2}$ emisyonları arasında doğrusal olmayan bir ilişkinin yanı sıra doğrudan yabancı yatırımlar ve $\mathrm{CO}_{2}$ arasında negatif bir ilişki olduğu sonucuna ulaşmışlardır.

İncelenen literatür değerlendirildiğinde zehirli atık miktarı ve ticaret ilişkisini ortaya koyan çalışmaların ağırlıklı olduğu özellikle gelişmekte olan ülkeler açısından konuyu ele alarak kirliliğe sebep olan üretimlerin gelişmekte olan ülkelerde yoğunluk kazandığına vurgu yapıldığı görülmektedir. Bunların yanı sıra ülkeleri gelirlerine göre sınıflandırarak konuyu inceleyen ve gelir düzeylerine bağlı kirlilik konusunu ele alarak literatüre katkı sağlayan çalışmalar da mevcuttur. Ancak bu çalışmalar ve literatürdeki birçok çalışmanın aksine kirlilik sığınağı hipotezini değil kirlilik hale hipotezini destekleyen ve bu açıdan literatüre katkı sağlayan eserler de bulunmaktadır.

Literatür genel olarak değerlendirildiğinde ağırlıklı olarak kirlilik sığınağı hipotezi çerçevesinde değerlendirmeler yapıldı ̆̆ , Çin ve Afrika ülkelerini araştıran çalışmaların bulunduğu, özellikle de Çin konusunda çok sayıda çalışma olduğu görülmektedir. Bu noktada tüm ülkeleri ya da gelişmekte veya gelişmiş ülke olarak gruplandırılan tüm kesimleri değerlendirme açısından güncel veri kısıtının bulunduğu görülmektedir. Türkiye açısından literatür değerlendirildiğinde veri kısıtı analizlerin belirli dönemler açısından yapılmasını mümkün kılmaktadır. Bu çalışma ile Türkiye açısından 1985-2017 dönemi için konu ele alınarak literatüre Türkiye'ye ilişkin katkı sağlanmaktadır. Özellikle kirlilik sığınağı ve kirlilik hale hipotezlerinin Türkiye özelinde birlikte ele alınması ve kullanılan değişkenler bakımından diğer çalışmalardan ayrılmaktadır. Aşağıda yer alan tabloda literatürdeki önemli çalışmalar ve içeriklerine ilişkin bilgiler yer almaktadır. 
Tablo 1: Kirlilik Sığınağı ve Kirlilik Hale Hipotezlerine ilişkin Çalışma Örnekleri

\begin{tabular}{|c|c|c|c|c|}
\hline Yazar & Kapsam & Dönem & Yöntem & Sonuç \\
\hline $\begin{array}{l}\text { Keller ve Levinson } \\
\text { (1999) }\end{array}$ & $\mathrm{ABD}$ & 1977-1994 & $\begin{array}{l}\text { En küçük kareler, } \\
\text { panel veri }\end{array}$ & $\begin{array}{l}\text { Kirlilik yoğun endüstrilerde } \\
\text { çevresel düzenlemelerden } \\
\text { kaçınılmaktadır. }\end{array}$ \\
\hline $\begin{array}{l}\text { List ve Co } \\
(2000)\end{array}$ & $\mathrm{ABD}$ & 1986-1993 & Logit modeli & $\begin{array}{l}\text { Eyaletler arasındaki çevre } \\
\text { politikaları farkı önemlidir. }\end{array}$ \\
\hline $\begin{array}{l}\text { Hoffmann ve ark. } \\
\text { (2005) }\end{array}$ & 112 Ülke & $1990-2005$ & $\begin{array}{c}\text { Granger } \\
\text { Nedensellik Testi }\end{array}$ & $\begin{array}{l}\text { Kirlilik Sı̆̆ınağı Hipotezi } \\
\text { yalnızca düşük gelirli } \\
\text { ülkelerde geçerli bulunmuştur. }\end{array}$ \\
\hline $\begin{array}{l}\text { Atic1 ve Kurt } \\
\text { (2007) }\end{array}$ & Türkiye & $1968-2000$ & $\begin{array}{l}\text { Regresyon } \\
\text { Analizi }\end{array}$ & $\begin{array}{l}\text { Kirlilik Sı̆̆ınağı Hipotezi } \\
\text { geçerlidir. }\end{array}$ \\
\hline $\begin{array}{l}\text { Asghari } \\
(2013)\end{array}$ & MENA & $1980-2011$ & Hausman Testi & $\begin{array}{l}\text { Kirlilik Hale hipotezi } \\
\text { geçerlidir. }\end{array}$ \\
\hline $\begin{array}{l}\text { Kivyiro ve Arminen } \\
(2014)\end{array}$ & $\begin{array}{c}\text { Kongo } \\
\text { Demokratik } \\
\text { Cumhuriyeti, } \\
\text { Kenya, Güney } \\
\text { Afrika, Zambiya } \\
\text { ve Zimbabve. }\end{array}$ & $2000-2012$ & $\begin{array}{c}\text { Granger } \\
\text { Nedensellik Testi }\end{array}$ & $\begin{array}{c}\text { Demokratik Kongo } \\
\text { Cumhuriyeti, Güney Afrika } \\
\text { ve Zambiya için Kirlilik Hale } \\
\text { hipotezi; geçerlidir. Zimbabwe } \\
\text { ve Kenya için Kirlilik Sığınağı } \\
\text { hipotezi geçerlidir. }\end{array}$ \\
\hline $\begin{array}{l}\text { Sapkota ve Bastola } \\
\text { (2017) }\end{array}$ & $\begin{array}{l}14 \text { Latin Amerika } \\
\text { Ülkesi }\end{array}$ & $1980-2010$ & Panel veri & $\begin{array}{l}\text { Kirlilik Sığınağı Hipotezi } \\
\text { geçerlidir. }\end{array}$ \\
\hline $\begin{array}{l}\text { Fang ve ark. } \\
\text { (2019) }\end{array}$ & Çin & 2003-2013 & $\begin{array}{l}\text { Endüstriyel firma } \\
\text { anketleri }\end{array}$ & $\begin{array}{l}\text { Kirlilik Sığınağı Hipotezi } \\
\text { geçerlidir. }\end{array}$ \\
\hline $\begin{array}{l}\text { Balsalobre, } \\
\text { Gökmenoğlu, ve } \\
\text { Taşpınar (2019) }\end{array}$ & MINT Ülkeleri & $1990-2013$ & Panel veri & $\begin{array}{l}\text { Kirlilik Sığınağı Hipotezi } \\
\text { geçerlidir. }\end{array}$ \\
\hline $\begin{array}{l}\text { Nadeem, Ali, Khan, ve } \\
\text { Guo }(2020)\end{array}$ & Pakistan & 1971-2014 & ARDL & $\begin{array}{l}\text { Kirlilik Sığınağı Hipotezi } \\
\text { doğrulanamamıştır. }\end{array}$ \\
\hline $\begin{array}{l}\text { Kisswani ve Zaitouni } \\
\text { (2021) }\end{array}$ & $\begin{array}{c}\text { Malezya, } \\
\text { Filipinler, } \\
\text { Singapur, Tayland }\end{array}$ & 1971-2014 & ARDL & $\begin{array}{c}\text { Filipinler için Kirlilik Sığınağ } 1 \\
\text { Hipotezi, Malezya ve Singapur } \\
\text { için Kirlilik Hale Hipotezi } \\
\text { geçerlidir. }\end{array}$ \\
\hline
\end{tabular}

Yukarıda yer alan tablo ve literatür incelemesi değerlendirildiğinde, çalışmaların ağırlıklı olarak Çin ve ABD’nin yanı sıra Afrika ülkelerini de kapsadığı görülmektedir. Özellikle doğrudan yabancı sermaye yatırımlarının çevresel kirlenmeyle ilişkisini ele alan çalışmalar ağırlıktadır. Çalışmaların önemli bir kısmında nedensellik analizlerine yer verilirken, Kuznets Eğrisi'ne yönelik modeller çerçevesinde Kirlilik Sığınakları ve Kirlilik Hale Hipotezleri incelenmiştir. List ve Co (2000)'nun çalışması bu alandaki öncü çalışmalar arasında yer almaktadır ancak kapsam bakımından 112 ülkeyi konu alan Hoffman ve ark. (2005) çalışması literatürdeki Çin ve ABD üzerine yoğunlaşan çalışmalardan farklı olarak ülke gruplarının incelenmesi ile literatüre önemli katkılar sağlamıştır. Çalışmalarda ağırlıklı olarak $\mathrm{CO}_{2}$ emisyon oranı, GSYİH ve doğrudan yabancı sermaye yatırım oranlarının analizlerde kullanıldığı görülmektedir. 


\section{Ampirik Analiz}

Bu çalışmada 1985-2017 yılları arasında Türkiye'nin kirlilik sığınağı hipotezinin sınanması amaçlanmıştır. Çalışmada birden fazla bağımsız değişken kullanılacak olmasından dolayı çoklu regresyon modeli kullanılacak olup parametre tahminleri ek küçük kareler yöntemi ile tahmin edilecektir. Ek küçük kareler yöntemi sabit ve eğim parametrelerinin tahmini amacıyla kullanılmaktadır ve güvenilir sonuçlar vermesinden dolayı literatürde en çok kullanılan yöntemlerden birisidir. Bu yüzden bu analiz için en uygun yöntem olduğu düşünülerek bu yöntem uygulanmıştır.

Bu amaçla Kirlilik Haddi (KH), GSYİH (GDP), GSYİH'nın karesi (GDP²), Doğrudan Yabancı Yatırımlar (FDI), Kentleşme (URB), Finansal Gelişim (FD) ve Ekolojik Ayakizi (EF) değişkenleri kullanılmıştır. KH değişkeni UN Comtrade-Commodity Trade Statistics Database'den, GDP, FDI, URB verileri Dünya Bankası Kalkınma İstatistilerinden, FD verisi IMF’ten ve EF verisi de Global Footprint Network’ten alınmıştır. EF değişkeni en son 2017 verisi açıklandığından modelde zaman serisi bu yıla kadar yapılabilmiştir.

Çalışmada iki model tahmin edilmiştir. Bunlardan birincisi KH'nin bağımsız değişken GDP, GDP², FDI ve URB değişkenlerinin bağımlı değişken olduğu Model 1'dir. Verilerin uç değer gözlemlerinin ortalamaya yakınsaması ve yüksek varyansından ayrılabilmesi amacıyla logaritmalarıyla çalışılmıştır.

$$
\ln \mathrm{KH}=\alpha \beta 1 \ln \mathrm{GDP}+\beta 2 \ln \mathrm{GDP}^{2}+\beta 3 \ln \mathrm{FDI}+\beta 4 \ln \mathrm{URB}+\varepsilon
$$

Tablo 2: Model 1 Regresyon Sonuçları

\begin{tabular}{lc}
\hline \multirow{2}{*}{ Değişkenler } & Bağımsız Değişken \\
\cline { 2 - 2 } & Model 1 InKH \\
\hline Sabit c & -10.6158 \\
p - val & 0.0051 \\
lnGDP & 14.8579 \\
p - val & 0.0455 \\
lnGDP 2 & -7.6602 \\
p - val & 0.0393 \\
lnFDI & 0.0939 \\
p - val & 0.0766 \\
lnURB & 1.2772 \\
p - val & 0.0615 \\
\hline R2 & 0.6686 \\
F & 14.1273 \\
D.W. & 1.4093 \\
\hline
\end{tabular}

Tablo 2'de Model 1'in regresyon sonuçları gösterilmiştir. Buna göre KH ile GDP değişkenleri arasında istatistiksel olarak anlamlı doğrusal bir ilişki söz konusudur. Yani 
ekonomik büyüme arttıkça kirlilik hadleri de yükselmektedir. GDP² ile KH istatistiksel olarak anlamlı ve negatif ilişki içerisindedir. FDI ile KH istatistiksel olarak anlamlı ve pozitif ilişki içerisindedir. Buna göre doğrudan yabancı yatırımlar arttıkça kirlilik hadleri de anlamlı olarak artmaktadır. Bu bulgu bize kirlilik sığınakları hipotezinin doğrulandığı sonucunu göstermektedir. Son olarak URB ile KH verisi istatistiksel olarak anlamlı ve pozitif ilişki içerisindedir. Kentleşme oranı arttıkça kirlilik hadleri de yükselmektedir. Bu durum tarım sektöründen sanayi sektörlerine istihdam geçişini de gösterdiğinden bu insanların daha çok kirlilik yaratan sektörlerde istihdam edildiğini göstermektedir.

İkinci model olarak kirlenme göstergesi seçilen EF'nin bağımsız değişken, GDP, FD, ve FDI'ın bağımlı değişken olarak seçildiği model 2 tahmini yapılmıştır. Ekolojik ayakizi değişkeni sera gazı salınımı indikatörlerine göre daha geniş kapsamlı olduğundan birçok güncel çalışmada tercih edilmektedir (Köksal, Işik, \& Katircioğlu, 2020).

$$
\ln \mathrm{EF}=\alpha \beta 1 \ln \mathrm{GDP}+\beta 2 \ln \mathrm{FD}+\beta 3 \ln \mathrm{FDI}+\varepsilon
$$

Tablo 3: Model 2 Regresyon Sonuçları

\begin{tabular}{|c|c|}
\hline \multirow{2}{*}{$\begin{array}{l}\text { Bağımlı } \\
\text { Değişkenler }\end{array}$} & $\begin{array}{l}\text { Bağımsız } \\
\text { Değişken }\end{array}$ \\
\hline & Model $2 \operatorname{lnEF}$ \\
\hline Sabit & 3.7835 \\
\hline $\mathrm{p}$ - val & 0.0061 \\
\hline LnGDP & 0.5664 \\
\hline $\mathrm{p}-\mathrm{val}$ & 0.0000 \\
\hline $\operatorname{lnFD}$ & 0.1124 \\
\hline $\mathrm{p}-\mathrm{val}$ & 0.0095 \\
\hline $\operatorname{lnFDI}$ & -0.0064 \\
\hline $\mathrm{p}$ - val & 0.6485 \\
\hline R2 & 0.9789 \\
\hline $\mathrm{F}$ & 448.613 \\
\hline D.W. & 2.0072 \\
\hline
\end{tabular}

Tablo 3'te gösterilen Model 2 regresyon sonuçlarına göre EF, GDP'ten pozitif olarak etkilenmektedir. Yani ekonomik büyüme çevre kirliliği yaratmaktadır. Bu sonuç yine kirlilik sığınağı hipotezini Türkiye örneğinde doğrular niteliktedir. FDI ile EF arasında anlamlı bir ilişki bulunamamıştır. Finansal gelişim verisi çevre kirliliğiyle pozitif ilişki içindedir. $\mathrm{Bu}$ durum bizi, Türkiye'de finansal sektörlerin çevre kirliliğine neden olacak türde temiz teknolojilerle üretim yapan sektörlere yeterince kaynak aktarmadığı sonucuna ulaştırmaktadır. Bazı güncel çalışmalar da bu durumu desteklemektedir (Kökssal, Katircioğlu, \& Katircioğlu, 2021).

Yapılan regresyon analizlerinin güvenilir tahminler verebilmeleri için sahip olmaları gereken varsayımlardan sapmaların varlığını sınamak için çeşitli testler yapılmalıdır. Normallik varsayımının geçerliliğini test edebilmek için Jarque-Bera testi uygulanmıştır. 
Tablo 4: Jarque-Bera Normallik Testi

\begin{tabular}{lcccc}
\hline & Jarque-Bera & Prob. Olasılık Değeri & Skewness (Eğiklik) & Kurtosis (Basıklık) \\
\cline { 2 - 5 } Model 1 & 0.2309 & 0.8909 & 0.0132 & 2.5910 \\
Model 2 & 3.6263 & 0.1631 & -0.7453 & 3.6443 \\
\hline
\end{tabular}

H0: Kalıntılar normal dağılmıștır.

H1: Kalıntılar normal dağılmamıştır.

Tablo 4'teki Model 1 Jarque-Bera normallik testine göre olasılık değeri 0,8909>0,05 olduğu için H0 hipotezi reddedilememektedir. Hata terimlerinin normal dağıldığ 1 sonucu ortaya çıkmaktadır. Aynı şekilde Tablo 4'teki Model 2 Jarque-Bera normallik testine göre olasılık değeri 0,1631>0,05 olduğu için H0 hipotezi reddedilememektedir. Yine hata terimlerinin normal dağıldığı sonucu ortaya çıkmaktadır.

Modelde otokorelasyon var olup olmadığını test etmek amacıyla Breusch-Godfrey LM testi uygulanmıştır. Gecikme değeri gözlemlerin yıllık olmasından dolayı uygun görülen değer olarak 1 alınarak hesaplanmıştır.

Tablo 5: Breusch-Godfrey Otokorelasyon Testi

\begin{tabular}{lcc}
\hline Model & Obs*R-squared & Prob. Chi-Square(1) \\
\hline Model 1 & 3,1245 & 0,0771 \\
Model 2 & 0,0153 & 0,9013 \\
\hline
\end{tabular}

H0: Otokorelasyon vardır.

H1: Otokorelasyon yoktur.

Tablo 5'e göre; her iki modelde de Prob. Chi-Square(1)>0.05 olduğu için H0 hipotezi reddedilir. Yani otokorelasyon olmadığı sonucuna varılır.

Sabit varyans varsayımının geçerliliğini test etmek için White ve Breusch-PaganGodfrey testleri uygulanmıştır.

Tablo 6: Sabit Varyans Testleri

\begin{tabular}{cccc}
\hline Model & Test & Obs*R-squared & Prob. Chi-Square(1) \\
\hline \multirow{3}{*}{ Model 1 } & White & 13.1193 & 0,1573 \\
Model 2 & Breusch-Pagan-Godfrey & 5,2625 & 0,2614 \\
& White & 15,8013 & 0,0711 \\
& Breusch-Pagan-Godfrey & 6,1634 & 0,1039 \\
\hline
\end{tabular}

Tablo 6'da sabit varyans olup olmadığını test edebilmek amacıyla Breusch-PaganGodfrey ve White testleri uygulanmıştır. Her iki modelin iki testinde de Prob $>0.05$ olduğundan $\mathrm{H} 0$ reddedilemez sonucuna varılır ve bu iki test de sabit varyans varsayımını kabul ettiği görülmektedir.

Kurulmuş olan modelin yapısal kırılma içerip içermediğini test edebilmek amacıyla CUSUM testi uygulanmıştır. 


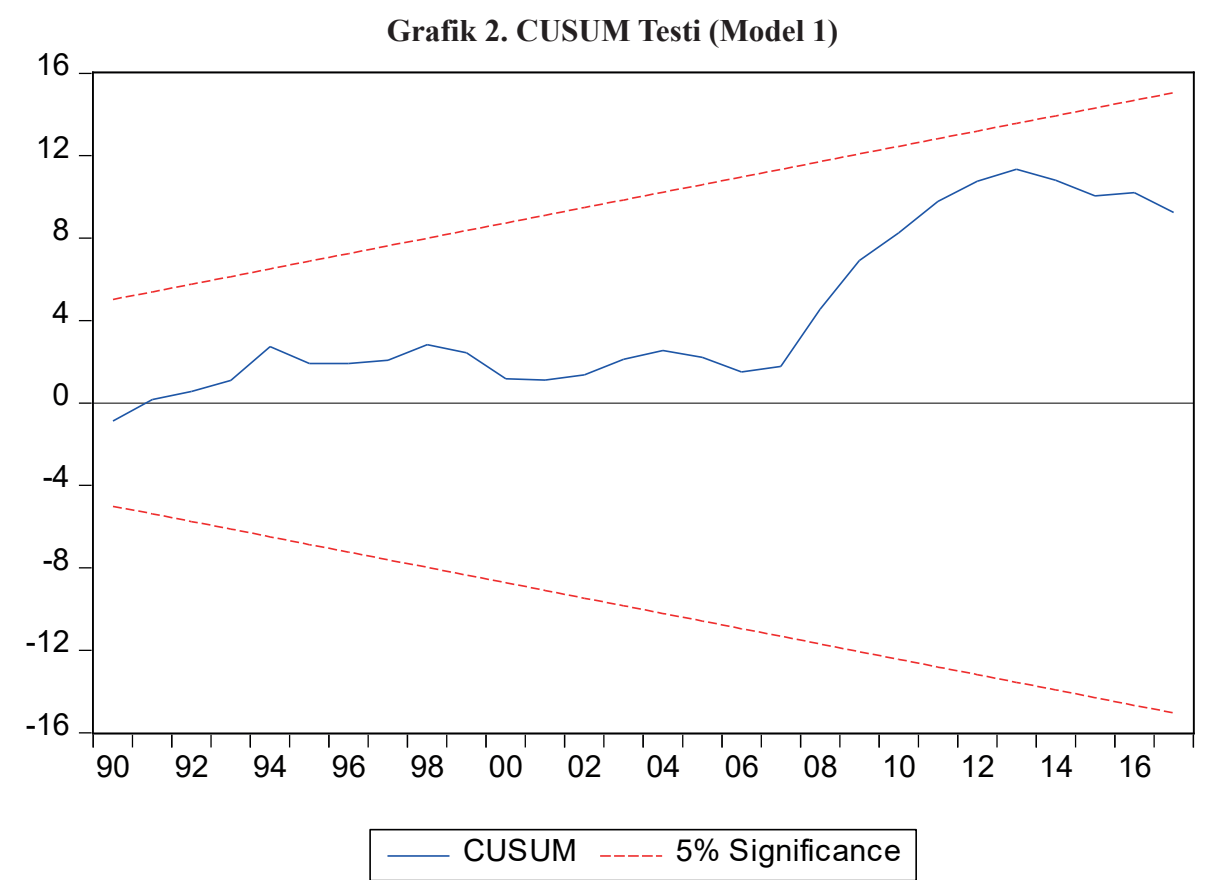

Grafik 2'de gösterildiği üzere CUSUM güven aralığı dişına çıkmadığından 1. modelde yapısal kırılmanın olmadığı sonucuna ulaşılabilir.

Grafik 3. CUSUM Testi (Model 2)

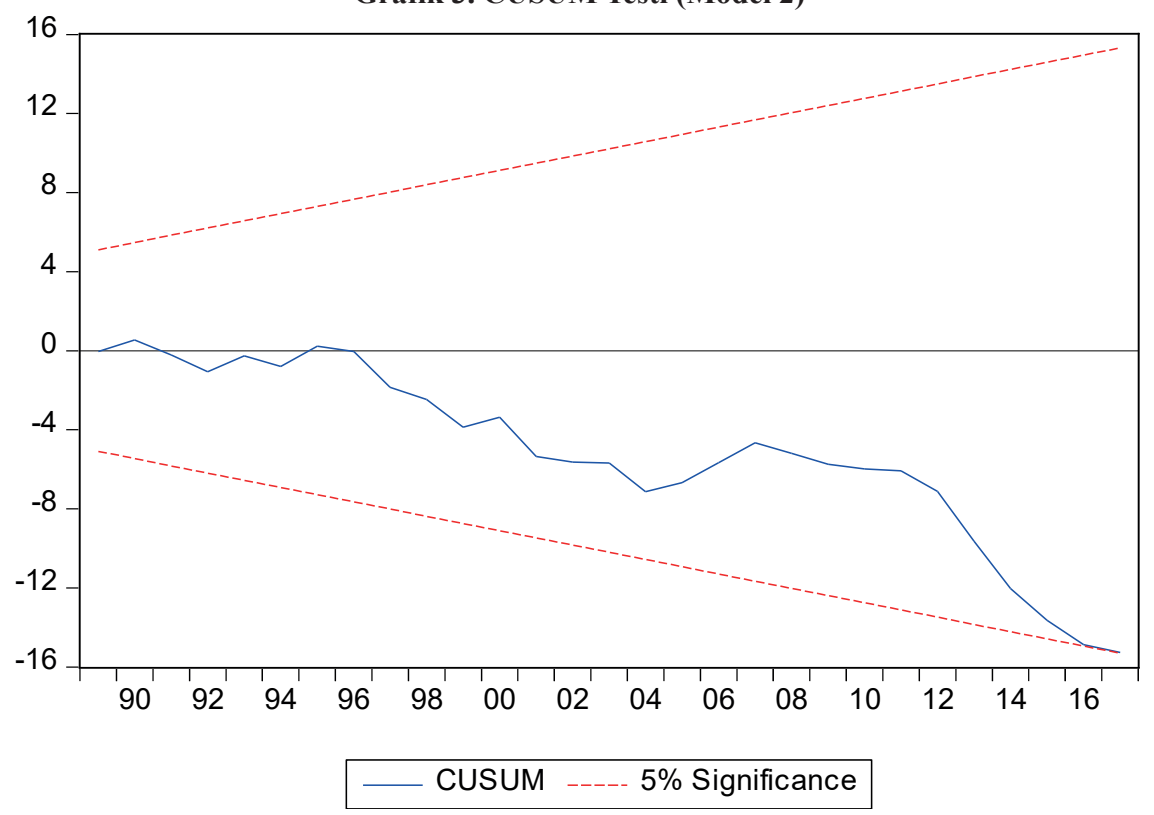


Grafik 3'te gösterildiği üzere CUSUM güven aralığı dışına çıkmadığından 2. Modelde de yapısal kırılmanın olmadığı sonucuna ulaşılabilir.

Yapılan tüm bu testler sonucunda kurulmuş olan modellerin ortaya koyduğu sonuçların güvenilir olduğu anlaşılmıştır.

Atıcı ve Kurt (2007) çalışmasında 1968-2000 yılları arasındaki verilerin kullanılarak regresyon analizinin ortaya koymuş olduğu gibi bu çalışmada da Kirlilik Sığınağı Hipotezi Türkiye örneğinde doğrulanmıştır. Mert ve Caglar (2020) çalışması da aynı şekilde Kirlilik Sığınağ1 Hipotezini incelenen 1974-2018 yılları arası için doğrulamıştır. Ancak bu çalışmalarda kirlilik değişkeni olarak $\mathrm{CO}_{2}$ kullanılmıştır. Mevcut çalışmada ise kirliliğin yalnızca sera gazı salınımı etkisi değil orman, deniz, ekilebilir araziler ve toprak gibi çeşitli diğer boyutlarını da hesaba katan ekolojik ayakizi verisi kullanılmıştır.

Diğer gelişmekte olan ülkeler için yapılan çalışmalara bakıldığında farklı sonuçlara ulaşılmıştır. Asghari (2013) MENA ülkeleri için yapmış olduğu analizde Kirlilik Hale Hipotezini doğrulayan sonuçlar bulmuştur. Kivyiro ve Arminen (2014) Kongo, Güney Afrika ve Zambiya için Kirlilik Hale Hipotezini destekleyen sonuçlar bulurken Zimbabwe ve Kenya için Kirlilik Sığınağı Hipotezini destekleyen sonuçlara ulaşmışlardır. Sapkota ve Bastola (2017) 14 Latin Amerika ülkesi için ve Fang ve ark. (2019) ve Xu ve ark. (2020) Çin için Kirlilik Sığınağı Hipotezini doğrulayan çalışmalar yapmışlardır. Bu çalışmalardan çıkarılabilecek sonuç gelişmekte olan ülkelerin büyük bir bölümünde Kirlilik Sığınakları Hipotezinin doğrulandığı yani bu ülkelerin gelişiminde kirlilik yaratan sektörlerin önemli bir rolü olduğunu ortaya koymaktadır.

\section{SONUÇ}

Bu çalışmada Türkiye'de kirlilik sığınağı hipotezinin geçerliliği 1985-2017 yılları arası için sınanmıştır. En küçük kareler yöntemi uygulanarak yapılan çok değişkenli regresyon analizi sonucunda Türkiye'nin incelenen dönemler içinde kirlilik üreten sektörlerde, çevresel düzenlemelerin çok sıkı olmamasından dolayı daha cazip bulunduğu ve doğrudan yabancı yatırımlar aracılığıyla bu sektörlerde daha fazla ihracat yapar hale geldiği görülmektedir. Buna göre doğrudan yabancı yatırımlar arttıkça kirlilik hadleri de anlamlı olarak artmaktadır. Bu bulgu bize kirlilik sığınakları hipotezinin doğrulandığı sonucunu göstermektedir. Ulaşılan bir diğer sonuç ise kirlilik hadleri yükseldikçe ekonomik büyüme bundan olumsuz etkilenmektedir ve kentleşme oranı arttıkça kirlilik hadleri de yükselmektedir. Bu durum ise bizi kırsal kesimden kente göçün daha çok kirlilik üreten sektörlerde istihdam edildiği sonucuna ulaştırmaktadır. İkinci modelde ise ekonomik büyüme çevre kirliliği yaratmaktadır sonucu ortaya çıkmıştır. Bu sonuç yine kirlilik sığınağı hipotezini Türkiye örneğinde doğrular niteliktedir. Finansal gelişim verisi çevre kirliliğiyle negatif ilişki içindedir. Bu 
durum bizi, Türkiye'de finansal sektörlerin çevre kirliliğine engel olacak türde temiz teknolojilerle üretim yapan sektörlere yeterince kaynak aktarmadığı sonucuna ulaştırmaktadır.

Çevresel Kuznets Hipotezinin öngördüğü dönüm noktasına geldikten sonra çevresel değişkenlerde düzelmelerin olması beklenmektedir. Bu durumun ortaya çıkabilmesi için Kyoto Protokolü, Paris İklim Anlaşması gibi uluslararası çevre anlaşmalarının yürürlüğe girmesinin yanında devletin ilave önlemlerle kirlilik yaratan sektörleri düzenleyerek çevreye zarar verebilecek atıkların kontrol altına alınmasını sağlayacağı yasal tedbirleri uygulayıp denetlemesi gereklidir. Türkiye'nin finansal sektörlerinin daha temiz sektörlere kaynak aktarmaya başlamaları sonucu bu anlamda önemli bir gelişme ve bulgu olarak ortaya çıkmaktadır. Reel sektörün de yenilenebilir enerji kaynaklarına yönelmesi, dış ticarette daha temiz sektörlere yönelmesi gibi gelişmelerin olması bu anlamda Türkiye'nin çevresel performansını geliştirebilecek niteliktedir.

Tüm bu analizler 1şı̆̆ında, iklim değişikliği, küresel ısınma ve doğal kaynakların tükenmesi riski gibi konuların giderek önemli hale geldiği günümüzde Türkiye açısından daha temiz teknolojilere geçiş yapmak, kirlilik üreten sektörlerin ihracatçısı durumundan ithalatçısı durumuna gelmeyi ve başta $\mathrm{CO}_{2}$ olmak üzere sera gazı salınımlarını azaltarak daha sürdürülebilir bir büyümeye geçiş yapmasını gerekli kılmaktadır. Bu bakımdan enerji üretiminde yenilenebilir enerjiye kademeli olarak geçiş yapmak, çevresel düzenlemelerin daha sıkı hale getirilmesi ve temiz teknolojiye dayalı üretim yapıp ihracat yapan firmaların teşvik edilmesi gibi politikalar kirlilik hadlerinin azaltılmasında önemli rol oynayacaktır.

Bundan sonraki çalışmalarda farklı değişkenler ve farklı zaman serilerinde kirlilik sığınağı hipotezinin ve kirlilik hale hipotezinin geçerliliği Türkiye ve diğer gelişmekte olan ülkeler için uygulanması politika yapıcılar için önemli bir yol gösterici olacaktır. Ayrıca ilerleyen yıllarda bu analizlerin tekrarlanarak Çevresel Kuznets Hipotezini test ederek Türkiye'nin hangi aşamada olduğunun analiz edilmesi ve kirlilik yaratan sektörlerinin diş ticaretinde nasıl bir gelişim olduğunun görülmesi politika yapıcılar açısından önemli bilgiler sağlayacaktır.

\footnotetext{
Hakem Değerlendirmesi: Dış bağımsız.

Çıkar Çatışması: Yazarlar çıkar çatışması bildirmemiştir.

Yazar Katkıları: Çalışma Konsepti/Tasarım- C.K.; Veri Toplama- C.K., G.Ç.; Veri Analizi/Yorumlama- C.K.; Yazı Taslağı- C.K., G.Ç.; İçeriğin Eleştirel İncelemesi- C.K., G.Ç.; Son Onay ve Sorumluluk- C.K., G.Ç.; Malzeme ve Teknik Destek- C.K., G.Ç.; Süpervizyon- C.K

Finansal Destek: Yazarlar bu çalışma için finansal destek almadığını beyan etmiştir.

Peer-review: Externally peer-reviewed.

Author Contributions: Conception/Design of Study- C.K.; Data Acquisition- C.K., G.Ç.; Data Analysis/Interpretation- C.K.; Drafting Manuscript- C.K., G.Ç.; Critical Revision of Manuscript- C.K., G.Ç.; Final Approval and Accountability- C.K., G.Ç.; Material and Technical Support- C.K., G.Ç.; Supervision- C.K.

Conflict of Interest: The authors have no conflict of interest to declare.

Grant Support: The authors declared that this study has received no financial support.
} 


\section{Kaynakça/References}

Asghari, M. (2013). Does FDI promote MENA region's environment quality? Pollution halo or pollution haven hypothesis, International Journal of Scientific Research in Environmental Sciences (IJSRES), 1(6), 92-100.

Atıcı, C., \& Kurt, F. (2007). Türkiye'nin dış ticareti ve çevre kirliliği: Çevresel Kuznets eğrisi yaklaşımı. Tarım Ekonomisi Dergisi, 13(2), 61-69.

Balsalobre-Lorente, D., Gokmenoglu, K. K., Taspinar, N., \& Cantos-Cantos, J. M. (2019). An approach to the pollution haven and pollution halo hypotheses in MINT countries. Environmental Science and Pollution Research, 26(22), 23010-23026.

Cheng, Z., Li, L., \& Liu, J. (2020). The impact of foreign direct investment on urban PM2.5 pollution in China. Journal of environmental management, 265, 110532, 1-13.

Çetinkaya, Ş. (2018). Kirlilik slğınă̆ hipotezi ve kirli endüstrilerin Türkiye ekonomisindeki yeri, II. Uluslararası Multidisipliner Çalışmalar Kongresi.

Çınar, S., Yılmazer, M., \& Fazlılar, T. A. (2012). Kirlilik yaratan sektörlerin ticareti ve çevre: Gelişmiş ve gelişmekte olan ülkeler karşılaştırması. Doğuş Üniversitesi Dergisi, 13(2),

212-226.

Dou, J., \& Han, X. (2019). How does the industry mobility affect pollution industry transfer in China: Empirical test on Pollution Haven Hypothesis and Porter Hypothesis. Journal of cleaner production, 217, 105-115.

Fang, J., Liu, C., \& Gao, C. (2019). The impact of environmental regulation on firm exports: Evidence from environmental information disclosure policy in China. Environmental Science and Pollution Research, 26(36), 37101-37113.

Global Footprint Network (2021) Ecological footprint Oakland, USA, (2021, 11 Nisan) Erişim Adresi: https:// footprintnetwork.org/

Gökalp, M., \& Yıldırım, A. (2004). "Dış ticaret-çevre etkileşimi ve kirlilik sı̆̆ınakları hipotezi: Türkiye uygulaması”. Yönetim ve Ekonomi Dergisi, 11(2), 99-114.

Hoffmann, R., Lee, C. G., Ramasamy, B., \& Yeung, M. (2005). FDI and pollution: A Granger causality test using panel data, Journal of International Development, 17, 311-317.

Keller, W., \& Levinson, A. (1999). Environmental compliance costs and foreign direct investment inflows to U.S. States, NBER Working Paper Series, 1-42.

Kisswani, K. M., \& Zaitouni, M. (2021). Does FDI affect environmental degradation? Examining pollution haven and pollution halo hypotheses using ARDL modelling. Journal of the Asia Pacific Economy, 1-27.

Kivyiro, P., \& Arminen, H. (2014). Carbon dioxide emissions, energy consumption, economic growth, and foreign direct investment: Causality analysis for Sub-Saharan Africa. Energy, 74, 595-606.

Köksal, C., Işik, M., \& Katircioğlu, S. (2020). The role of shadow economies in ecological footprint quality: Empirical evidence from Turkey. Environmental Science and Pollution Research, 27, 13457-13466.

Köksal, C., Katircioğlu, S., \& Katircioğlu, S. (2021). The role of financial efficiency in renewable energy demand: Evidence from OECD countries. Journal of Environmental Management, 285, 112-122.

List, J.A., \& Co, C.Y. (2000). The Effects Of Environmental Regulations On Foreign Direct Investment. Journal of Environmental Economics and Management, 40(1), 1-20.

Low, P., \& Yeates, A. (1992). Do dirty industries migrate. P. Low (Ed.) International Trade and the Environment, World Bank Discussion Paper, No. 159, 89-104.

Mert, M., \& Caglar, A. E. (2020). Testing pollution haven and pollution halo hypotheses for

Turkey: A new perspective, Environmental Science and Pollution Research, 27(26), 32933-32943. 
Nadeem, A. M., Ali, T., Khan, M. T., \& Guo, Z. (2020). Relationship between inward FDI and environmental degradation for Pakistan: An exploration of pollution haven hypothesis through ARDL approach. Environmental Science \& Pollution Research, 27(13), 15407-15425.

Pethig, R. (1976). Pollution, welfare, and environmental poolicy in the theory of comparative

advantage. Journal of Environmental Economics and Management, 2(3), 160-169.

Polloni-Silva, E., Ferraz, D., Camioto, F. D. C., Rebelatto, D. A. D. N., \& Moralles, H. F. (2021). Environmental kuznets curve and the pollution-halo/haven hypotheses: An investigation in Brazilian Municipalities. Sustainability, 13(8), 4114, 1-19

Repkine, A., \& Min, D. (2020). Foreign-funded enterprises and pollution halo hypothesis: A spatial econometric analysis of thirty Chinese Regions. Sustainability, 12(12), 5048, 1-24.

Sapkota, P., \& Bastola, U. (2017). Foreign direct investment, income, and environmental pollution in developing countries: Data analysis of Latin America. Energy Economics, 64, 206-212.

Şahinöz, A., \& Fotourehchi, Z. (2014). Kirlilik Emisyonu ve Doğrudan Yabancı Sermaye Yatırımları: Türkiye İçin “Kirlilik Sı̆̆ınağı Hipotezi” Testi. Sosyoekonomi, 21(21), 187-210.

Tobey, J. A. (1990). The Effect of Domestic Environmental Policies, Kyklos, 43(2), 191-209.

UN Comtrade. (2021). Commodity Trade Statistics Database, (2021, 11 Nisan) Erişim Adresi: comtrade.un.org

Xu, H., Zhao, G., Xie, R., \& Zhu, K. (2020). A trade-related CO2 emissions and its composition: Evidence from China. Journal of Environmental Management, 270, 110893, 1-14.

$\mathrm{Xu}$, Y., Dietzenbacher, E., \& Los, B. (2020). International trade and air pollution damages in the United States. Ecological Economics, 171, 106599.

Yıldırım, M., Destek, M., \& Nakıpoğlu, Ö. F. (2017). Doğrudan yabancı yatırımlar ve kirlilik sığınağı hipotezi. Cumhuriyet Üniversitesi İktisadi ve İdari Bilimler Dergisi, 18(2), 99-111.

World Bank, (2021). World Development Indicators, (2021, 11 Nisan) Erişim Adresi: dataworldbank.org

Zeren, F. (2015). Doğrudan yabancı yatırımların $\mathrm{CO}_{2}$ emisyonunaetkisi: Kirlilik hale hipotezi mi kirlilik cenneti hipotezi mi?. Journal of Yaşar University, 10(37), 6442-6448. 
